\title{
Apparatus for Demonstrating Newton's Laws
}

\author{
Studying Motion Accelerated Under the Action of a Constant Force \\ By H. W. Harmon, Grove City College, Grove City, Pa.
}

Mos's of the standard text-books in physics and mechanics, under the topic of Newton's Second Law of Motion, give more or less space to the discussion and solution of problems concerning the tensions in cords attached to accelerated bodies, using the cables attached to rapidly ascending and descending elevators for their illustration.

Several years ago it seemed desirable to design an apparatus suitable for our students in the physical laboratory, to test out these principles experimentally. The difficulty met with at once was to find a practical method of measuring these tensions while the bodies were in such rapid motion. Finally, the apparatus shown in the diagram was developed and has been in use by our students for the last two or three years. As inertia, acceleration, changes of momentum, and reaction are all involved in the experiment, it goes with us under the name of the Newton's Laws Experiment. Referring to the diagram, Figs. 1 and 2 show a top and front view of the apparatus. The body to be accelerated is a car shown in Figs. 3 and 4, arranged to be variously loaded. It slides over the surface of a hard wood box about 18 feet long and 2 -inch by 4 -inch section. The car is released from its starting position by the action 'of the electromagnet $(H)$ shown in Fig. 3 and operated by the clock pendulum, Fig. 2, making and breaking contact. The car is accelerated by the unbalanced weight of the mass $M_{1}$, which may also accelerate $M_{2}$ if it is attached to the rear of the car, as shown in Fig. 2. The cord connecting the car and $M_{1}$ passes over a frictionless pulley mounted on the movable arm shown in Fig. 5. It is apparent by a glance at the spring balance $(B)$ in Fig. 2 , that the tension $\left(T_{1}\right)$ in the cord connecting $M_{1}$ and the car will be registered by balance $B$, if allowance be made for the weight of the arm and a slight leverage action of the pulley itself. By this simple scheme we were enabled to measure the tensions in the cord attached to the accelerated body regardless of the high velocities attained.

A curve card is plotted in which the weight of the arm and the leverage of the pulley is allowed for, and by its use, balance readings can be taken off from the curve as true tensions $\left(T_{1}\right)$

'iths balance conection is made as follows: With the pulley arm in the horizontal position and the tension $T$ zero, the balance was found to read 125 grammes, owing to the weight of the arm. This weight is included in all cases in the reading of $B$. But more or less completely neutralizing this weight of the pulley arm is an upward component of the tension $\left(=2 / 32 T_{1}\right)$, for as used in this position the pulley, the pulley wheel and arm constitute a right-angled, bent arm lever with power arm equal to the radius of the pulley ( 2 centimeters), and the weight arm equal to the length of the pulley arm ( 32 centimeters). With this correction for pulley arm (32 centimeters). With this correction for balance reading $B$ with the tension $T_{1}$ will then be: $B=125+T_{1}-\frac{1}{16} T_{1}$.

To draw the correction curve, remember that whe $T_{1}=0$, then $B=125$ grammes; when $T_{1}=125 g$ $B=T_{1}=2,000$ grammes. Locate these two points on a sheet of cross-section paper by the usual method and sheet of cross-section paper by the usual method and
draw a straight line through them. (See halance cordraw a straight line through

To keep the car on the track, the bar has a half round groove formed in it through its entire length, and corresponding half round runner is fastened to the bottom of the car. To keep the friction constant, the sliding surfaces are kept uniformly polished and oiled with heavy oil. The high velocities attained, 5 meters per second or more in some trials, are reduced without too much shock by the friction clutch and rubber cushion shown in Fig. 1. The velocity of $M_{2}$, when attached, is reduced to zero by a spring or gum tube $(G)$ attached to a trailing cord which goes into operation at the sam time the friction clutch does on the car, while $M_{1}$ is brought to rest in the box of cotton waste shown in Fig. 2.

When the apparatus was first put into practical use the car was released by a trigger operated by hand and the timing done with a stop-watch. Thus operated, the errors due to timing gave results in which the percentage of error was in some trials quite large. Recently we have mounted on the car an electromagnet $(E)$ shown in Fig. 4, which is arranged in series with the releasin electromagnet $(H)$. The armature of this magnet, pivoted to move up and down, has a spring brass wire soldered to it, extending over the back end of the car and bent down near the surface of the sliding track, where it terminates in a piece of chamois skin moistened with well thinned printer's ink. This is shown in Fig. 6 by $I$. The electric current is led to the car by two wires, one stretched taut down the back side of the bar; the second one is stretched down a second half round groove in the top of the bar. Contact brushes $B B$ for these are shown in Fig. 6. The inker marks off on the bar distances covered in even seconds as beaten

the gramme as the unit of mass,

$$
F_{a}=\frac{M a}{980}
$$

where $F_{a}$ is the unbalanced force, $M$ is the total mass accelerated, and $a$ the acceleration.

In our present problem the total mass $M$ is given by $M=M_{2}+M_{2}+W$

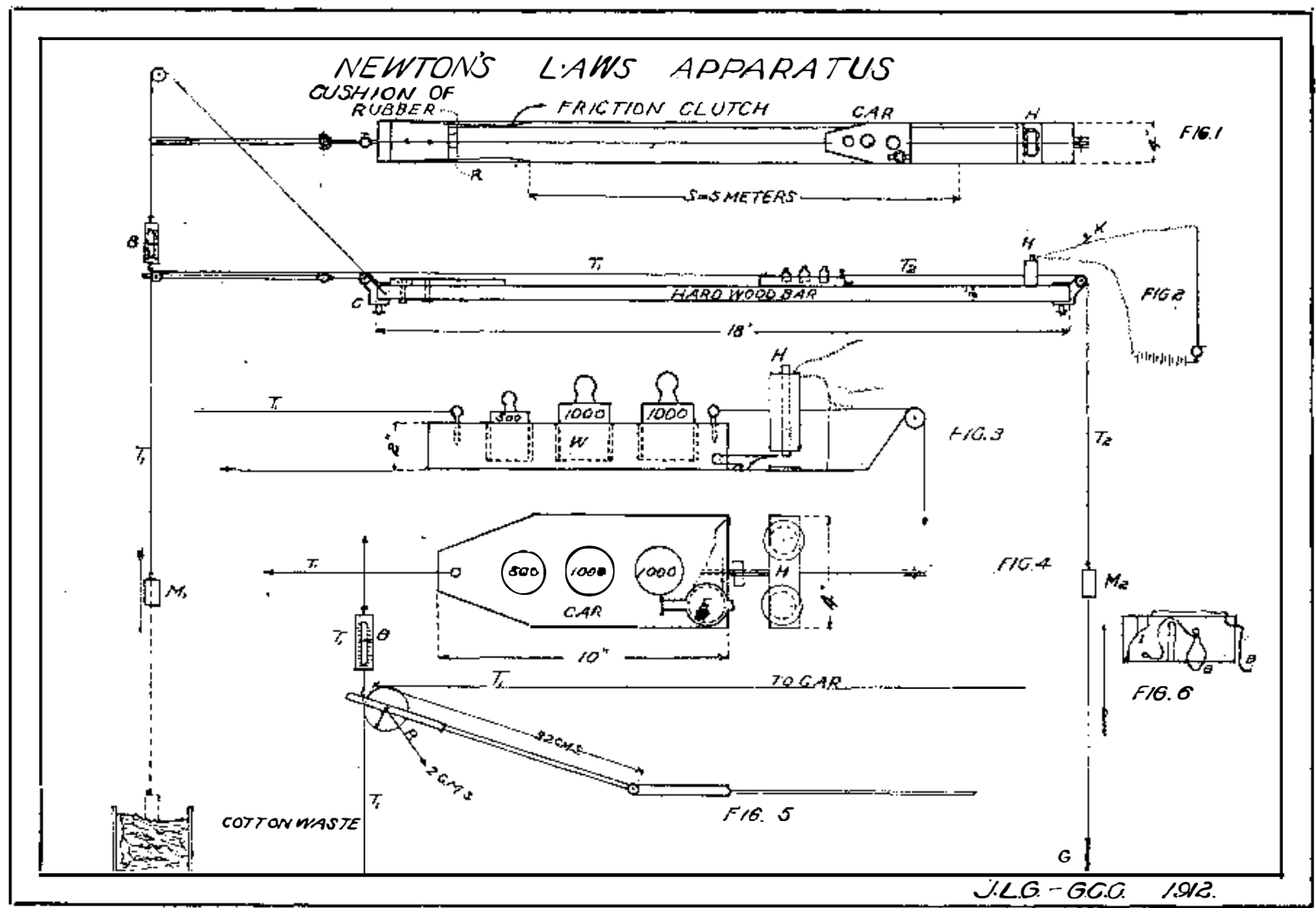

off by the seconds pendulum of the laboratory clock. The slotted weights which go to make up $M_{1}$ are so chosen that the unbalanced force in the various trials of the experiment causes the car to make its run down to the clutch in just slightly over 2 seconds.

The inker operates very accurately, for, even in those trials in which the car is traveling 500 centimeters per second, successive trials seldom differ by more than two or three centimeters in the total distance covered in the 2 seconds' time of run. used. This indicates that the combined error of the inker and release magnet does not exceed 1/200th of a second in the timing. Since equipped with this improved timing device, the apparatus has given very satisfactory results, as can be seen by an examination of the data table. The errors remaining are almost entirely due to balance readings and friction measurements.

The friction is found for each trial as the car is differently loaded. This is done by placing on the weight support, $M_{1}$, such slotted weights as will cause the car, when started, to move down the track with a slow uniform motion. In those trials when $M_{2}$ is attached to the form motion. In those trials when $M_{2}$ is attached to the
rear of the car, the total of the slotted weights thus needed, less the weight of $M_{2}$, is called the friction. METHOD AND THEORY OF EXPERIMENT.

First clean, oil and polish the sliding surfaces, then load the car as required and find the friction $\left(F_{f}\right)$ as above. The required weights are next placed on the $M_{1}$ weight holder and the car placed at its starting position and held by the trigger ready to be released, following the closing of the electric switch $(k)$ in the clock cirthe closing of the electric switch $(k)$ in the clock cir-
cuit. When the car is released and is speeding down cuit. When the car is released and is speeding down
the track toward the friction clutch, one observer watches the index of balance $B$, and takes its reading. This is usually repeated three times, and the average reading of $B$ is taken, corrected by reference to the curve card and recorded as $T_{1}$.

At the same time, for each of these runs, the distance the car has traveled in 2 seconds, as marked off by the inker, is measured, and these distances a veraged $(=S)$. The unbalanced force $\left(F_{a}\right)$, which causes the car and attached masses to be accelerated as it runs down the track, is the difference between the weight of $M_{1}$ and the friction $\left(F_{f}\right)$ and also less $M_{2}$ if it is attached.

Newton's second law enables us to compute what this acceleration $a$ will be. If absolute units are used, the equation is

$F_{a}=M a$

or, using the gramme-weight as the unit of force, and where $W$ is the mass of the car and load. The acceleration $a$ as computed by the formula

$$
a=\frac{980 F_{a}}{M}=\frac{980 F_{a}}{M_{1}+M_{2}+W}
$$

( $F_{a}$ being measured in grammes weight) should agree with $a$ computed from

$$
\begin{gathered}
s=\frac{1}{2} a t^{2} \\
a=\frac{2 s}{t^{2}}
\end{gathered}
$$

The tension $T_{1}$ in the cord connecting $M_{1}$ and $W$ is equal to the sum of the frictional force $F_{f}$ (measured in grammes weight) of the weight $980 M_{2}$ of the mass $M_{2}$, if attached, and of the unbalanced accelerating force $F_{a^{\prime}}=\frac{\left(W+M_{2}\right) a}{980}$ grams. weight acting on $W$ and $M_{2}$. Thus $T_{1}=F_{f}+M_{2}+\frac{\left(W+M_{2}\right) a}{0}$

This should agree with the corrected balance readThis

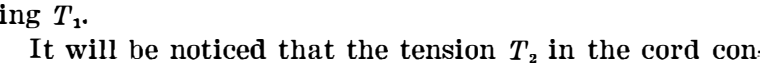
It will be noticed that the tension $T_{2}$ in the cord con-
necting the car with the mass $M_{2}$ is not observed experimentally by a balance and movable arm as is the tension $T_{1}$ in the leading cord attached to $M_{1}$. This could be done in the same way, but it is not deemed necessary for this experimental test to be repeated.

When the car is at its starting position, held by the trigger, the mass $M_{1}$ hanging at rest at the end of the cord exerts a tension $\left(T_{1}\right)$ in the cord that is exactly

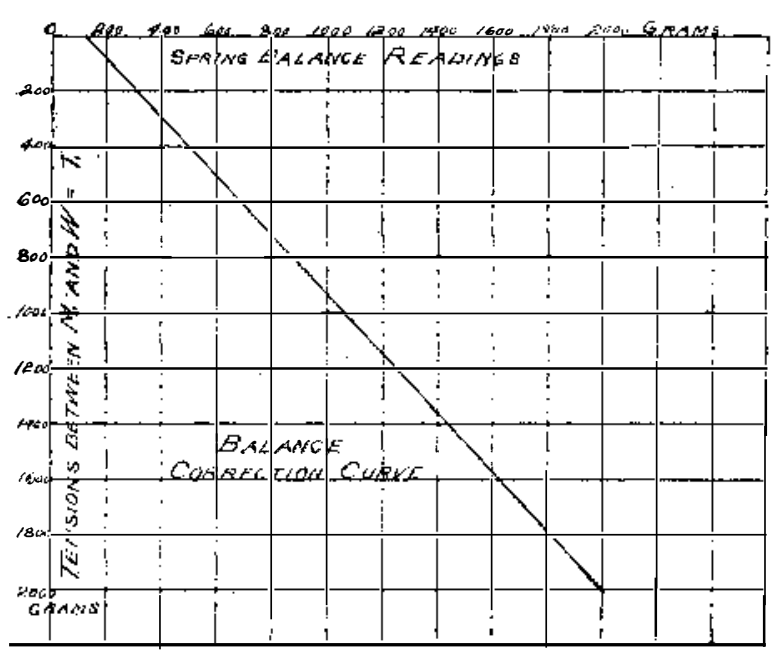


equal to its weight. The weight of $M_{1}$ at rest is fully effective in producing tension. A freely falling bod has no effective weight, for its weight force is all used in accelerating it. A falling body only slightly accelerated has a proportional part of its weight effective (i. e., a man in a descending elevator). This effective weight approaches zero as $(a)$ approaches $(g)$ in value when $(g)$ equals an acceleration of 980 centimeters per second per second, or 32.16 feet per second per second; and the weight of a body approaches full effectivenes as. (a) approaches zero. We shall therefore expect to find the values of $T_{1}$ always less than $M_{1}$, and $T_{2}$ always greater than $M_{2}$, for $M_{2}$ is accelerated upward, and $T_{2}$ consists of both the weight of $M_{2}$ and the force which consists of both the weight of $M_{2}$ and the force which
is accelerating $M_{2}$. Reference to the data table shows these expectations realized.
In looking into the factors which enter into this experiment, inertia, momentum, impulse, friction, and tension, it is seen that Newton's Three Laws are all fully involved, and also the laws of accelerated motion. A knowledge of most of the terms used in mechanics is necessary. This therefore should make an especially effective experiment for the junior student in physics or the student making a special study in mechanics.

\begin{tabular}{|c|c|c|c|c|c|c|c|c|c|c|c|c|c|c|c|c|c|}
\hline & \multicolumn{3}{|c|}{ Masses } & \multirow{3}{*}{$\underset{\mathrm{Ff}}{\text { Friction }}$} & \multirow{3}{*}{\begin{tabular}{|c} 
Coefficient \\
of Friction \\
$\mathrm{F}_{f} \div \mathrm{W}=\mathrm{C}$
\end{tabular}} & \multirow{3}{*}{$\begin{array}{c}\text { Space } \\
\text { S }\end{array}$} & \multirow{3}{*}{$\underset{t}{\text { Time }}$} & \multicolumn{3}{|c|}{ Acceleration } & \multicolumn{4}{|c|}{ Tension between } & \multicolumn{3}{|c|}{ Unbala nced Accelerating Force On } \\
\hline & \multirow{2}{*}{$\underset{\mathbf{M}_{1}}{\stackrel{+}{\text { Mass }}}$} & \multirow[b]{2}{*}{$\underset{\mathrm{W}}{\mathrm{I}}$} & \multirow{2}{*}{$\overline{\substack{\text { Mass } \\
\mathbf{M}_{2}}}$} & & & & & \multirow{2}{*}{$\begin{array}{c}\text { Observed }= \\
2 s ; t^{2} \\
=A\end{array}$} & \multirow{2}{*}{$\begin{array}{c}\begin{array}{c}\text { Computed }= \\
980 \mathrm{~F}_{3}\end{array} \\
\begin{array}{c}\mathrm{W}+\mathrm{M}_{1}+\mathrm{M}_{2}= \\
\mathrm{A}^{\prime}\end{array}\end{array}$} & \multirow{2}{*}{ 畜 } & \multicolumn{2}{|c|}{$\mathrm{M}_{1}$ and $\mathrm{W}$} & \multirow{2}{*}{ 崖 } & \multirow{2}{*}{$\begin{array}{l}\mathrm{W} \text { a and } \mathrm{M}_{2} \\
=\mathrm{M}_{2}+\mathrm{F}_{\mathbb{F}^{\prime \prime}} \\
\mathrm{T}_{2}\end{array}$} & \multirow{2}{*}{$\begin{array}{c}\mathbf{M}_{1}+\mathbf{M}_{2}+\mathbf{W} \\
\mathbf{M}_{1}-\left(\mathbf{M}_{2}+\mathbf{F}_{\mathrm{f}}\right) \\
=\mathbf{F} \mathbf{F}\end{array}$} & \multirow{2}{*}{$\begin{array}{c}\begin{array}{c}\mathrm{W}+\mathrm{M} \\
\left(\mathrm{W}+\mathrm{M}_{2}\right) \mathrm{a}\end{array} \\
\mathbf{9 8 0} \\
=\mathrm{Fa}^{\prime}\end{array}$} & \multirow{2}{*}{$\begin{array}{l}\mathbf{M}_{2} \\
\mathbf{M}_{22} \\
980 \\
=F^{\prime \prime}\end{array}$} \\
\hline & & & & & & & & & & & $\left|\begin{array}{c}\text { Observed } \\
\mathbf{T}_{1}\end{array}\right|$ & $\begin{array}{c}\text { Computed } \\
\mathbf{F}_{t}+\mathrm{F}_{4}+\mathbf{M}_{2} \\
=\mathbf{T}_{1}\end{array}$ & & & & & \\
\hline & grms. & grms. & grms. & 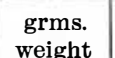 & & $\mathrm{cm}$. & secs. & cms. per sec. & cms. per sec. & $\%$ & $\begin{array}{c}\text { grms. } \\
\text { weight }\end{array}$ & $\begin{array}{l}\text { grms. } \\
\text { weijht }\end{array}$ & $\%$ & $\begin{array}{l}\text { grms. } \\
\text { weight }\end{array}$ & grms. & grms. & grms. \\
\hline 1 & 1,865 & & 0 & & .272 & 391.0 & 2.0 & & & 0.0 & 1,4 & & & & & & \\
\hline & & & 0 & & & & & & & 1.7 & 1,0 & 1.101 & & & & & \\
\hline 3 & & & $\begin{array}{l}0 \\
0\end{array}$ & & .268 .268 & & 2.0 & & & 2.7 & 85 & 874 & $\begin{array}{cc}2.2 \\
09\end{array}$ & & 61 & & \\
\hline 4 & $\begin{array}{l}7 \\
1,9\end{array}$ & $\begin{array}{l}1,66 \\
66\end{array}$ & $\begin{array}{c}0 \\
1,000\end{array}$ & $\begin{array}{l}30 \\
27\end{array}$ & .40 & & $\begin{array}{l}2.0 \\
2.0\end{array}$ & & & $\begin{array}{l}4.4 \\
1.2\end{array}$ & & & $\begin{array}{l}0.9 \\
1.8\end{array}$ & & & & \\
\hline 6 & 2,3 & & 1,000 & $39:$ & .372 & 413 & 2.0 & & 20 & 1.7 & 1,78 & & 2.5 & $\begin{array}{l}1,1 \\
1,2\end{array}$ & & & 10 \\
\hline 7 & & & & 440 & .323 & & 2.0 & & & 1.6 & & & 3.0 & & & & 107 \\
\hline 8 & 2,2 & 2,1 & 50 & 620 & .287 & 440 & 2.0 & & 220 & 0.1 & 1,680 & 1,7 & 2 & 61 & 1,0 & 59 & 112 \\
\hline $\begin{array}{r}9 \\
10\end{array}$ & $\begin{array}{l}1,815 \\
1,915\end{array}$ & $\begin{array}{l}2,360 \\
2,660\end{array}$ & $\begin{array}{l}200 \\
200\end{array}$ & $\begin{array}{l}620 \\
700\end{array}$ & .264 & $\begin{array}{l}443.2 \\
416.0\end{array}-150$ & $\begin{array}{l}2.0 \\
2.0\end{array}$ & 208 & $\begin{array}{l}222.7 \\
208.2\end{array}$ & $\begin{array}{l}0.5 \\
0.1\end{array} \mid$ & $\begin{array}{l}1,395 \\
1,497\end{array}$ & $\begin{array}{l}1,399 \\
1,506\end{array}$ & $\left|\begin{array}{c}0.3 \\
0.6\end{array}\right|$ & ${ }_{243}^{243}$ & $\begin{array}{r}995 \\
1,015\end{array}$ & 579 & $\begin{array}{l}45 \\
42.5\end{array}$ \\
\hline
\end{tabular}

Sudden Changes in the Form of Liquid Crystals* By 0. Lehmann

FonmerLy science assumed matter to be continuous, although porous; to be chemically as well as physically homogeneous; the molecular arrangement changing of course in case of anisotropy at the border line between differently oriented parts of a body, in case of crystals, which may, however, be defined as aggregates. For example a spherical crystal has been considered an aggregate; whereas, according to my findings, it may be an individual.

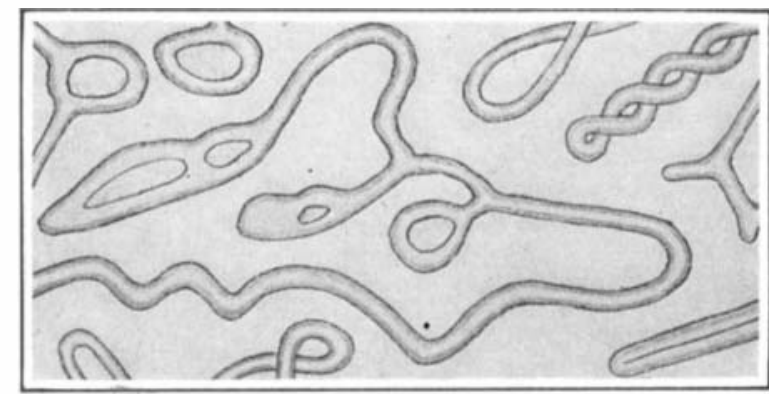

Fig. 1.

Likewise plastically distorted crystals (of ' gold, silver, etc.) were held to be aggregates of crystal fragments, while the existence of liquid crystals was wholly excluded from the realm of possibility by the "Theory of Identity" (molecular identity in the solid and liquid states), crystallization being made synonymous wit states), crystallization being made synonymous with
solidification, only two sorts of molecular arrangement the lattice-like order in the crystal and entire irregula ity in the molten mass, being considered possible.

My discovery of transparent plastic crystals, whose distortion causes no fragment formation, together with the discovery that by the admixture of foreign substances permanent distortion of crystals can be secured first justifies the question: "Are such distorted crystals still to be regarded as individual units, or are they ag gregates as formerly supposed?" Must we distinguis between true crystalline plasticity, where the crysta remains a unit (for example, soft glass) and apparent plasticity, where a crystalline unit becomes an aggregate of fragments, the only sort of plasticity recognized un to the present?

The further discovery that the form of silver iodide stable above 146 degrees, formerly considered amorphous-viscous, was really crystalline, naturally raise the further question, "Can true plasticity go so far that a crystal may be considered fluid, thus contradicting the 'Theory of Identity?'”

I first obtained absolute proof of the existence of liquid crystals with ammonium-oleate hydrate. The proof rests on the demonstration that these crystals possess no "limit of elasticity," as the term is understood relative to solids; for the molecular equilibrium is automatically restored after any distortion; there fore, the crystals must be considered liquid, not solid.

When liquid crystalline ammonium-oleate is drawn into a capillary tube, the molecules arrange themselves radially, with optical axes perpendicular to the walls of the tube. Now, if a short piece of such a tube is placed in water the liquid crystalline mass swells out at either end into cylindrical myelin forms (liquid

* Translated from Annalen der Physili for the ScIEnTific AMERICAN SuPPLEMENT. crystals), consisting of a modification of ammoniumoleate of identical structure with that in the tube. Thus the existence of myelin forms is a complete contradiction to the above-mentioned assumption that a chemically homogeneous body must be physically homogeneous, for these myelin forms are not aggregates of crystal units, no boundaries being anywhere observable. Nevertheless, points near the surface are by no means equivalent to those near the axis; therefore the matter is not continuous. The existence of liquid crystals, es pecially of the myelin sort, is then a certain proof of the molecular theory.

The existence of liquid crystals also contradicts the accepted theory that only two forms of molecular arrangement can exist, the one entirely irregular, the other, the lattice-like order in crystals.

If, as I first supposed, the molecules are tiny rods, they must be radially arranged when sucked into a capillary tube; hence any current in the mass would alter the lines of interference, since internal friction would retard motion near the tube wall and give the molecules there situated an oblique direction. This does not occur, therefore I now assume molecules to be tiny flat plates, whose surfaces are perpendicular to the optical axis. Other phenomena support this assumption.

Accordingly a cylindrical myelin crystal is in a sense an aggregate of co-axial cylinders of regularly placed plate-like molecules, these cylinders being closed on the ends by hemispheres of like radius.

This peculiar structure demands anisotropy of thermic motion and of expansile force. The molecules easily glide over one another in a direction parallel to their flat surfaces, therefore expansion in the direction of the cylinder axis is greater than in the direction perpendicular to the axis; the cylinder must then reach sueh a thickness that the greater capillary pressure of the hemispherical ends must exactly balance the excess of expansile force.

It has not yet been possible to demonstrate thermic movements and their anisotropy by the observation of the Brownian movement, and since constant transitions from liquid to solid crystals occur it is very possible that the force hindering the surface tension from compressing the liquid crystal into a sphere (myelin forms) is not alone the force of expansion, but primarily the molecular directive force. A proof of this I believe I have discovered in the peculiar behavior of the myelin forms of ammonium-oleate and of protagon when cooled below -4 degrees.

\section{MMONIUM-OLEATE HYDRATE}

At ordinary temperatures the myelin liquid crystals of ammonium-oleate are jelly-like threads, easily bent, showing no elasticity, and no tendency to break even when bent double.

If liquid crystalline ammonia is placed under a large watch crystal shaped cover glass and ordinary ammonia allow to flow around and over the preparation, and the preparation set over night in a cool place, then such myelin forms as shown in Fig. 1 will be obtained. Now place these in a temperature of about -6 degree and they will take on the zig-zag shapes- of Fig. 2. We conclude that in the softer forms (Fig. 1) the molecules adjacent to one another in the direction of the long axis of a cylindrical surface form very blunt angles with one another; and that the straightening of the cylinders in the stable modification at the lower temperature is to be explained by the combination of the plate-like molecules into complicated molecules, which in turn are flat plates. The work done is a process of direct transformation of chemical into mechanical energy. PROTAGON, PHRENOSIN, AND KERASIN.

Protagon behaves practically like ammonium-oleate hydrate. Phrenosins can be obtained in thin plate-like crystals. The liquid crystals obtained on heating these with water take the shape of cylindrical myelin crystals, resembling ray-like projections, and these on cooling suddenly, shrink suddenly to half their length. If methelyn blue is added to the water in which phrenosin crystals are allowed to swell, so that the water is only tinged, the crystal becomes intensely blue

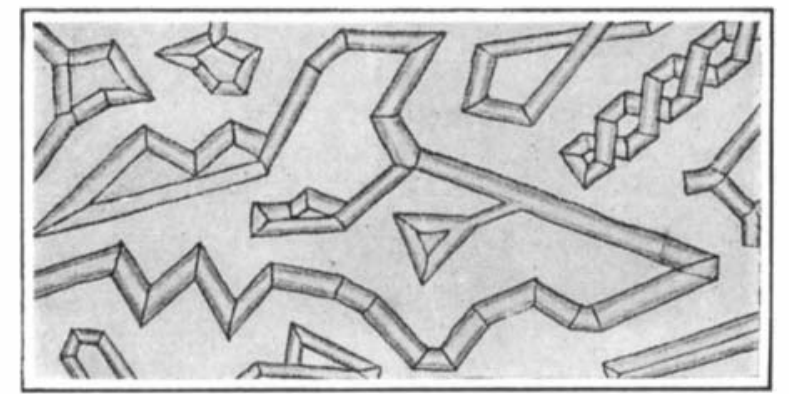

Fig. 2

(probably through chemical combination). When on cooling the sudden shrinking above mentioned takes place the blue changes to red violet.

Kerasin acts much like phrenosin, expanding and ontracting in the same way.

The myelin forms of protagon often lie one within another like the layers of an onion; forms open on one side drawing in, and ejecting smaller forms on solidifying and melting. They remind one of protoplasmic structures. Form and structure are, however, maintained purely by cohesion and molecular directive force, and not by an inclosing membrane.

\section{A Dog-Proof Fence}

THE Department of Apriculture in a recent issue of its "Weekly News Letter" tells farmers how to build a dog-proof fence that will safely protect sheep from the ravages of these animals. The posts should be $7 \frac{1}{2}$ feet long, set $2 \frac{1}{2}$ feet into the ground, and spaced 16 feet apart. Along the surface of the ground stretch a barbed wire, this to discourage any attempts to crawl or burrow under. At three inches from the ground stretch 36-inch woven wire fencing having a 4-inch triangular mesh. Above this woven fencing, and at intervals, respectively, of 5, 6, and 7 inches three strands of barbed wire are stretched, making the total height of the fence 57 inches. This fence is very durable and inexpensive to build, and it is stated that it will keep out any dog.

\section{Forest Fire Prevention}

THE prevention of serious damage from forest fires depends largely on prompt information and quick work in checking and preventing the spreading of such fires. In some districts the officials of the Forest Service of the Department of Agriculture have enlisted the interest of residents of their region with excellent results. A recent report of this department states that, in addition to his own fire detection system, the supervisor of the Palisade national forest, Idaho, was notified of each fire loy from five to ten different local settlers, who thus showed their co-operation in working for fire suppression. 